\title{
Ecological Stoichiometry
}

Subjects: Ecology

Submitted by: Michał

Filipiak

\section{Definition}

Ecological stoichiometry considers how nutritional needs of organisms for basic body-building molecules shape their ecology. It asks how nutritional demands of organisms and supply of nutrients in their environments affects organisms growth, their interactions with the biotic and abiotic worlds and nutrient cycling in whole ecosystem.

\section{Introduction}

The quality of food resources is crucial for animal growth, development and population dynamics. Therefore, limitations are posed on organisms because of food scarcity in specific nutrients. These limitations may shape ecological interactions and affect cycling of nutrients in the ecosystem. To better understand nutrient cycling driven by nutritional constraints posed on organisms, their communities and populations the ecological stoichiometry framework was developed (Figure 1). This research framework capitalizes on organisms to be composed of identical building blocks - atoms of chemical elements - even though they build remarkable diversity of organic molecules having diverse functions $[\underline{1}][\underline{2}][\underline{3}]$. During growth and development organisms assimilate all the building blocks needed to compose the adult body. The body is built of atoms in taxonomically specific proportion known as the organismal stoichiometry[르. The demand for resources gathered during juvenile growth is reflected in organismal stoichiometry of adult body and stoichiometric mismatch (Figure 2) may occur between the atomic composition of the body and food[1][ㄹ] . Even toxic effects may in fact be caused by such stoichiometric mismatch rather than true toxic substances ${ }^{[5]}$. 


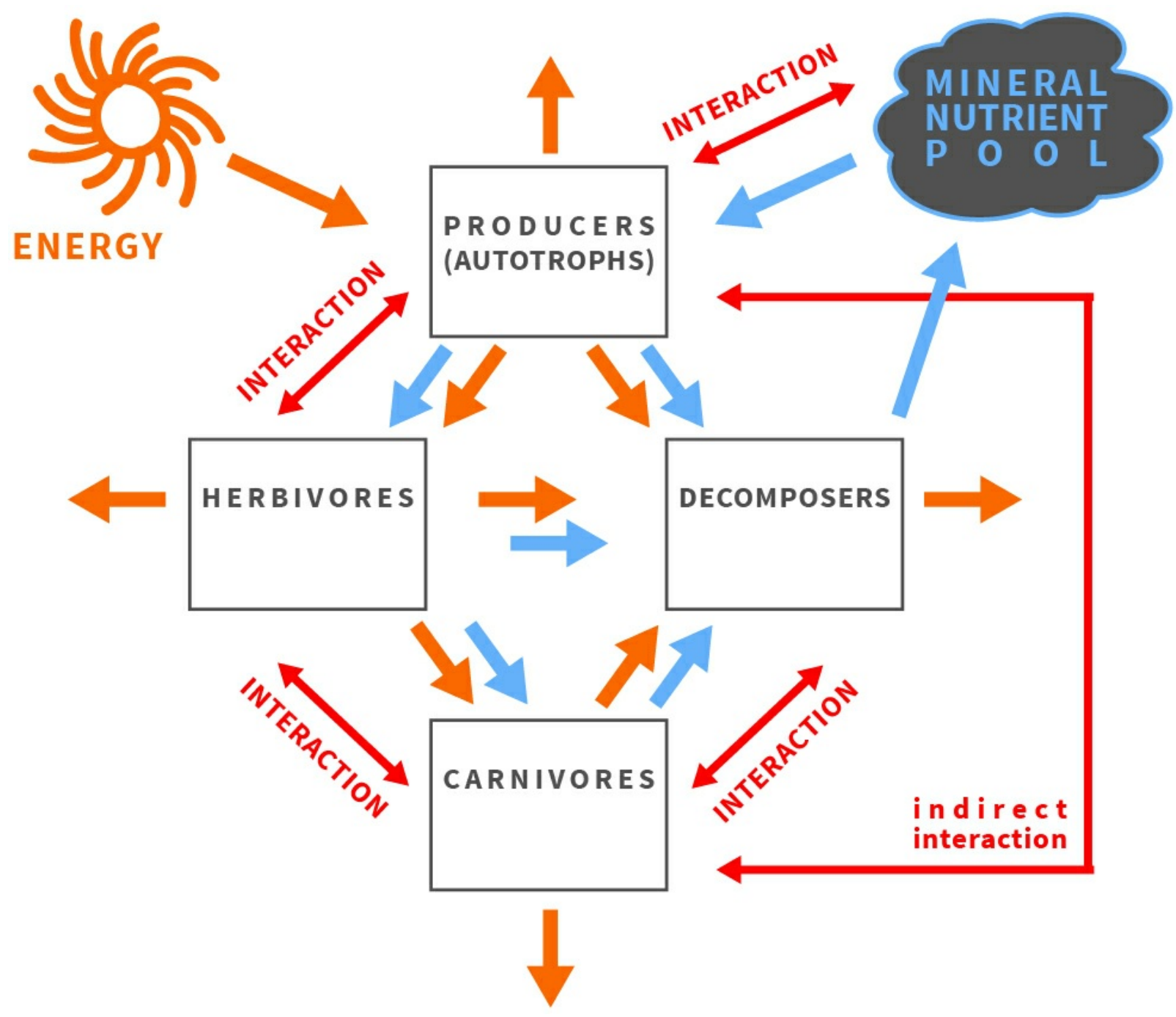

Figure 1. The balance of energy and matter affects and is affected by organisms and their interactions in an ecosystem.

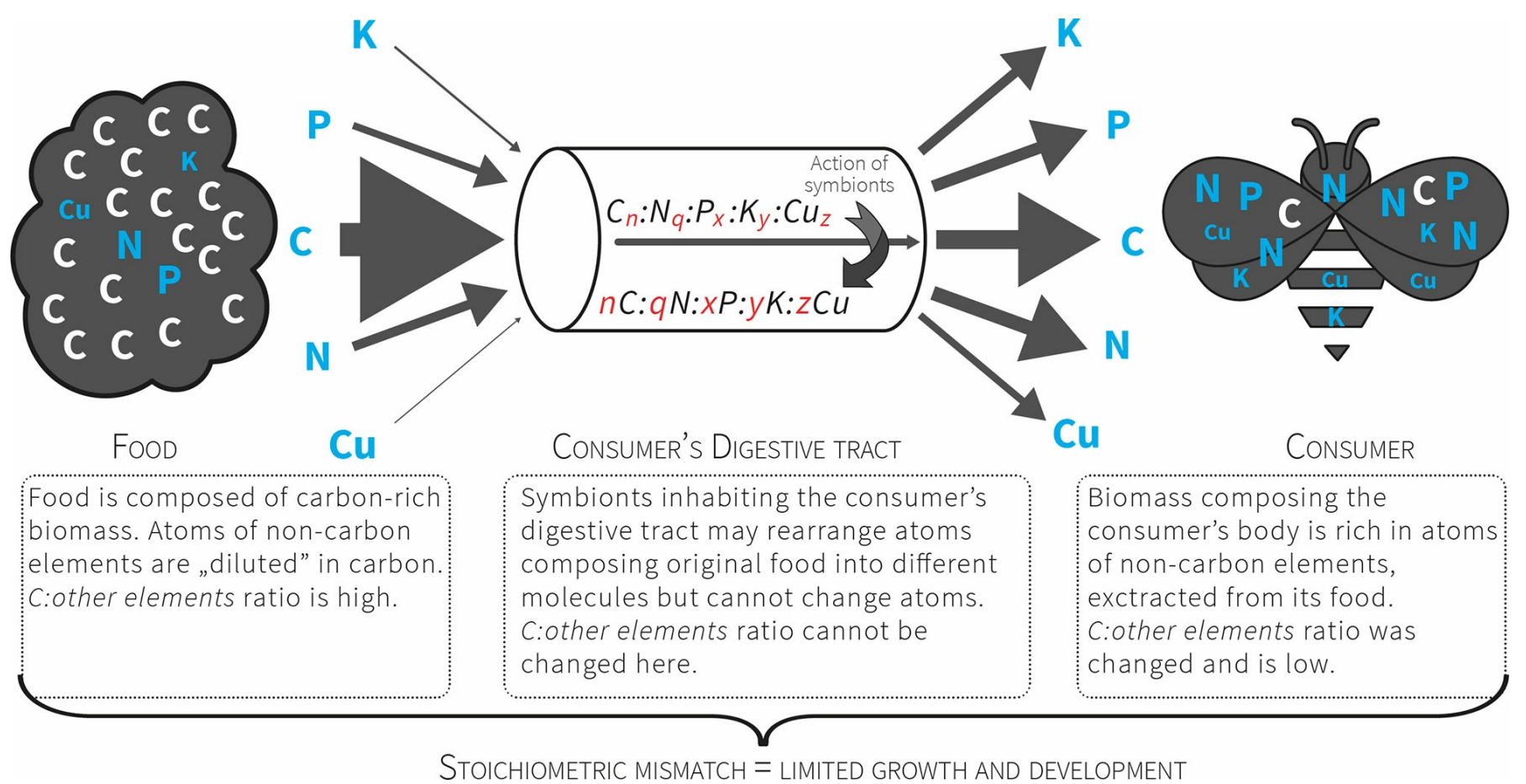

Figure 2 Consumers that feed on nutritionally poor food (e.g. plant matter) consume a pre-packaged ratio of atoms. For herbivores the food contains more $\mathrm{C}$ relative to other atoms, so these organisms must manage a diet with excess $C$ that presents a stoichiometric mismatch that limits their growth and development. The mismatch is further increased by unbalanced relation between non- $C$ elements (exceptional scarcity of some of them). 


\section{History}

The framework of ecological stoichiometry was envisioned in the works of Wiernadski[]]ㅁ], Liebig, Playfair and Webster ${ }^{[\underline{8}]}$, Lotka ${ }^{[9]}, \operatorname{Tilman}^{[\underline{10]}}$ and Reiners ${ }^{[\underline{11}]}$; postulated explicitly as a fruitful approach by Sterner and Hessen[12], Elser et al. [13][14][15]; and described in detail in the seminal book of Sterner and Elser ${ }^{[1]}$. The synthesis written by Sterner and Hessen[12], which focuses on nutrient limitations of aquatic herbivores, was recognized as a landmark paper that stimulated ecologists to broaden the understanding of producer-consumer interactions while considering ecological stoichiometry[16]. The essential ideas and living-systems characteristics of ecological stoichiometry are as follows: (1) the law of conservation of mass and immutable atoms flowing through the food chain; (2) the capability of living organisms to transform organic substances; (3) stoichiometric stability ("homeostasis"), in which every species has a unique composition of chemical elements in the body tissues, with heterotrophs showing a lower level of variability than autotrophs; and (4) consumer-driven nutrient recycling (CNR), in which the flow of matter through the food chain is regulated by the elemental body composition of species, thereby composing particular links in the chain $\underline{1}][\underline{4}]$.

\section{Current status}

It was noted recently that it is easier to find in the scientific literature a population's genome than its elemental composition [1]7]. At the same time, the concept of stoichiometric niche was introduced and defined as the region of multivariate niche space occupied by a group of individuals where the axes represent their elemental content $[\underline{18][19]}$. If a consumer is unable to find food that fits its stoichiometric niche, a limitation will be imposed on its growth and development that negatively influences its fitness, and the entire population may be negatively impacted in this way[2][그. In this way all consumers, especially herbivores, are faced with a high threshold of stoichiometric incompatibility between the chemical composition of their tissues and their food (Fig. 2). Ecological stoichiometry raises questions concerning the strategies of crossing this threshold (the advantages and costs involved) and how these strategies affect the structure of communities and ecosystem functioning. The strategies for crossing stoichiometric thresholds are still poorly understood.

The atoms of chemical elements build the tissues and bodies of organisms in various proportions. This fact is crucial for ecological interactions and may shape the functioning of entire ecosystems $[\underline{1}][\underline{20]}$. The most fundamental feature of the elements, enabling their use in ecological stoichiometry, is that specific atoms cannot be transformed into different atoms by the organism. This feature distinguishes atoms from organic compounds. Within this context, ecological stoichiometry provides a common currency that links the ecology of organisms to life history trade-offs and evolutionary processes entrenched in the biogeochemical economy of life ${ }^{[2]}$. This currency is the ratio of atoms that compose the bodies of organisms and their food $[\underline{1}]$.

To date, ecological stoichiometry has provided data on elemental composition patterns in different trophic levels, with non-C element body contents tending to be the lowest in autotrophs, relatively low in herbivores and the highest in predators. Stoichiometric homeostasis has been shown be weaker in autotrophs and stronger in heterotrophs ${ }^{[\underline{1}]}$. Ecological stoichiometry has also revealed stoichiometric mismatches at various trophic levels and has elucidated nutrient cycling in food webs $[\underline{1}][\underline{20}][\underline{21}]$. However, these studies were conducted almost exclusively in aquatic ecosystems[22]][23][24]][25][ㅌ]. Recent studies have researched nutrient cycling in soil ecosystems and the relationship between stoichiometry and

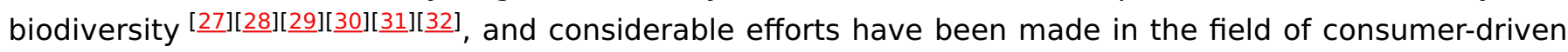
nutrient recycling theory (e.g., $[\underline{33}][\underline{34}][\underline{35}][\underline{36}]$ ). Nevertheless, much still needs to be done, since only $\mathrm{C}, \mathrm{N}$ and $P$ have been studied in this respect (e.g., [37]; see ${ }^{[23]}$ for a review). Notwithstanding, multielemental ecological stoichiometry approach has been used to explain the paradox of the efficient life strategy of wood eaters [38], to show the role of pollen in nutrient cycling [39], to learn about sex differences in stoichiometric phenotypes and stoichiometric niches ${ }^{[40]}$, to gain new knowledge about nutritional ecology of western honey bee ${ }^{[\underline{41}]}$ and to develop effective strategies for wild bee conservation [느][프] . 


\section{References}

1. Sterner RW; Elser JJ. Ecological Stoichiometry: The Biology of Elements from Molecules to the Biosphere; Princeton University Press: Princeton, NJ, 2002; pp. 464.

2. Adam D Kay; Isabel W. Ashton; Elena Gorokhova; Andrew J. Kerkhoff; Antonia Liess; Elena Litchman; Toward a stoichiometric framework for evolutionary biology. Oikos 2005, 109, 6-17, 10.1111/j.0030-1299.2005.14048.x.

3. A.D. Kay; T. Vrede; Evolutionary and Biochemical Aspects. Encyclopedia of Ecology 2008, na, 1472-1481, 10.1016/b978-008045405-4.00305-0.

4. Michał Filipiak; January Weiner; Plant-insect interactions: the role of ecological stoichiometry. Acta Agrobotanica 2017, 70, e, 10.5586/aa.1710.

5. Ruth H. Jones; Nutritional Status and Diet Composition Affect the Value of Diatoms as Copepod Prey. Science 2005, 307, 1457-1459, 10.1126/science.1107767.

6. Vernadsky, W. La Géochimie; Alcan: Paris, 1924; pp. 404.

7. Smil, V. Cycles of Life: Civilization and the Biosphere; Scientific American Library: New York, 2000; pp. 221.

8. Justus Liebig; Lyon Playfair Playfair; John White Webster; Chemistry in its application to agriculture and physiology.. Chemistry in its application to agriculture and physiology. 1843, na, na, 10.5962/bhl.title.41248.

9. Lotka, AJ. Elements of Physical Biology; Williams and Wilkins Co.: Baltimore, Md, 1925; pp. 460.

10. Tilman, D. Resource competition and community structure. Monographs in Population Biology; Princeton University Press: Princeton, NJ, 1982; pp. 296.

11. William A. Reiners; Complementary Models for Ecosystems. The American Naturalist 1986, 127, 59-73, $10.1086 / 284467$.

12. R W Sterner; D O Hessen; Algal Nutrient Limitation and the Nutrition of Aquatic Herbivores. Annual Review of Ecology and Systematics 1994, 25, 1-29, 10.1146/annurev.es.25.110194.000245.

13. James J. Elser; Dean R. Dobberfuhl; Neil A. Mackay; John H. Schampel; Organism Size, Life History, and N:P Stoichiometry. BioScience 1996, 46, 674-684, 10.2307/1312897.

14. James J. Elser; William F. Fagan; Robert F. Denno; Dean R. Dobberfuhl; Ayoola Folarin; Andrea F Huberty; Sebastian J Interlandi; Susan S. Kilham; Edward McCauley; Kimberly L. Schulz; et al.Evan H. SiemannRobert W. Sterner Nutritional constraints in terrestrial and freshwater food webs. Nature Cell Biology 2000, 408, 578-580, 10.1038/35046058.

15. J.J. Elser; R.W. Sterner; E. Gorokhova; W.F. Fagan; T.A. Markow; J.B. Cotner; J.F. Harrison; S.E. Hobbie; G.M. Odell; L.W. Weider; et al. Biological stoichiometry from genes to ecosystems. Ecology Letters 2000, 3, 540-550, 10.1046/j.14610248.2000.00185.x.

16. Philip W. Boyd; 2017 ASLO Awards. Limnology and Oceanography Bulletin 2017, 26, 44-50, 10.1002/lob.10169.

17. Michael Kaspari; Jennifer S. Powers; Biogeochemistry and Geographical Ecology: Embracing All Twenty-Five Elements Required to Build Organisms. The American Naturalist 2016, 188, S62-S73, 10.1086/687576.

18. Angélica L. González; Olivier Dézerald; Pablo A. Marquet; Gustavo Q. Romero; Diane S. Srivastava; The Multidimensional Stoichiometric Niche. Frontiers in Ecology and Evolution 2017, 5, na, 10.3389/fevo.2017.00110.

19. Josep Peñuelas; Marcos Fernández-Martínez; Philippe Ciais; David Jou; Shilong Piao; Michael Obersteiner; Sara Vicca; Ivan A. Janssens; Jordi Sardans; The bioelements, the elementome, and the biogeochemical niche. Ecology 2019, 100, e02652, 10.1002/ecy.2652.

20. Mehdi Cherif; Biological Stoichiometry: The Elements at the Heart of Biological Interactions. Stoichiometry and Research - The Importance of Quantity in Biomedicine 2012, na, na, 10.5772/34528.

21. Nina Welti; Maren Striebel; Amber J. Ulseth; Wyatt F. Cross; Stephen Devilbiss; Patricia M. Glibert; Laodong Guo; Andrew G. Hirst; Jim Hood; John S. Kominoski; et al.Keeley L. MacNeillAndrew S. Mehringjill R. WelterHelmut Hillebrand Bridging Food Webs, Ecosystem Metabolism, and Biogeochemistry Using Ecological Stoichiometry Theory. Frontiers in Microbiology 2017, 8, 1298-1298, 10.3389/fmicb.2017.01298.

22. S. J. Moe; Robert S. Stelzer; M. Rebecca Forman; W. Stanley Harpole; Tanguy Daufresne; Takehito Yoshida; Recent advances in ecological stoichiometry: insights for population and community ecology. Oikos 2005, 109, 29-39, 10.1111/j.0030-1299.2005.14056.x.

23. C. A. Klausmeier; E. Litchman; T. Daufresne; S. A. Levin; Phytoplankton stoichiometry. Ecological Research 2008, 23, 479-485, 10.1007/s11284-008-0470-8.

24. Jordi Sardans; Albert Rivas-Ubach; Josep Peñuelas; The elemental stoichiometry of aquatic and terrestrial ecosystems and its relationships with organismic lifestyle and ecosystem structure and function: a review and perspectives. Biogeochemistry 2011, 111, 1-39, 10.1007/s10533-011-9640-9.

25. Dag O. Hessen; James J. Elser; Robert W. Sterner; Jotaro Urabe; Ecological stoichiometry: An elementary approach using basic principles. Limnology and Oceanography 2013, 58, 2219-2236, 10.4319/lo.2013.58.6.2219.

26. Nathan P. Lemoine; Sean T. Giery; Deron E. Burkepile; Differing nutritional constraints of consumers across ecosystems. Oecologia 2014, 174, 1367-1376, 10.1007/s00442-013-2860-z.

27. Thomas D Schneider; Katharina M Keiblinger; Emanuel Schmid; Katja Sterflinger-Gleixner; Günther Ellersdorfer; Bernd Roschitzki; Andreas Richter; Leo Eberl; Sophie Zechmeister-Boltenstern; Kathrin Riedel; et al. Who is who in litter 
decomposition? Metaproteomics reveals major microbial players and their biogeochemical functions. The ISME Journal 2012, 6, 1749-1762, 10.1038/ismej.2012.11.

28. Maike Abbas; Anne Ebeling; Yvonne Oelmann; Robert Ptacnik; Christiane Roscher; Alexandra Weigelt; Wolfgang W. Weisser; Wolfgang Wilcke; Helmut Hillebrand; Biodiversity Effects on Plant Stoichiometry. PLoS ONE 2013, 8, e58179, 10.1371/journal.pone.0058179.

29. David Ott; Christoph Digel; Björn Christian Rall; Mark Maraun; Stefan Scheu; Ulrich Brose; Unifying elemental stoichiometry and metabolic theory in predicting species abundances. Ecology Letters 2014, 17, 1247-1256, 10.1111/ele.12330.

30. Anton M. Potapov; Irina I. Semenyuk; Alexei V. Tiunov; Seasonal and age-related changes in the stable isotope composition ( $15 \mathrm{~N} / 14 \mathrm{~N}$ and $13 \mathrm{C} / 12 \mathrm{C}$ ) of millipedes and collembolans in a temperate forest soil. Pedobiologia 2014, 57, 215-222, 10.1016/j.pedobi.2014.09.005.

31. Jofre Ecarnicer; J. Sardans; Constantí Stefanescu; Andreu Ubach; Mireia Bartrons; Dolores Asensio; Josep Epenuelas; Global biodiversity, stoichiometry and ecosystem function responses to human-induced C-N-P imbalances.. Journal of Plant Physiology 2014, 172, 82-91, 10.1016/j.jplph.2014.07.022.

32. Aleksandra M. Lewandowska; Antje Biermann; Elizabeth T. Borer; Miguel A. Cebrián-Piqueras; Steven A. J. Declerck; Luc De Meester; Ellen Van Donk; Lars Gamfeldt; Daniel S. Gruner; Nicole Hagenah; et al.W. Stanley HarpoleKevin P. KirkmanChristopher A. KlausmeierMichael KleyerJohannes M. H. KnopsPieter LemmensEric M. LindElena LitchmanJasmin Mantilla-ContrerasKoen MartensSandra MeierVanessa MindenJoslin L. MooreHarry Olde VenterinkEric W. SeabloomUlrich SommerMaren StriebelAnastasia TrenkampJuliane Trinoggajotaro UrabeWim VyvermanDedmer B. Van De WaalClaire E. WiddicombeHelmut Hillebrand The influence of balanced and imbalanced resource supply on biodiversity-functioning relationship across ecosystems. Philosophical Transactions of the Royal Society of London. Series B: Biological Sciences 2016, 371, 20150283, 10.1098/rstb.2015.0283.

33. James J. Elser; Jotaro Urabe; THE STOICHIOMETRY OF CONSUMER-DRIVEN NUTRIENT RECYCLING: THEORY, OBSERVATIONS, AND CONSEQUENCES. Ecology 1999, 80, 735-751, 10.1890/00129658(1999)080[0735:tsocdn]2.0.c0;2.

34. Michelle A. Evans-White; Gary A. Lamberti; Stoichiometry of consumer-driven nutrient recycling across nutrient regimes in streams. Ecology Letters 2006, 9, 1186-1197, 10.1111/j.1461-0248.2006.00971.x.

35. Antonia Liess; Jens Olsson; Mario Quevedo; Peter Eklöv; Tobias Vrede; Helmut Hillebrand; Food web complexity affects stoichiometric and trophic interactions. Oikos 2006, 114, 117-125, 10.1111/j.2006.0030-1299.14517.x.

36. Lesley B. Knoll; Peter B. McIntyre; Michael J. Vanni; Alexander S. Flecker; Feedbacks of consumer nutrient recycling on producer biomass and stoichiometry: separating direct and indirect effects. Oikos 2009, 118, 1732-1742, 10.1111/j.1600-0706.2009.17367.x.

37. Paul C. Frost; Jonathan P. Benstead; Wyatt F. Cross; Helmut Hillebrand; James H. Larson; Marguerite A. Xenopoulos; Takehito Yoshida; Threshold elemental ratios of carbon and phosphorus in aquatic consumers. Ecology Letters 2006, 9, 774-779, 10.1111/j.1461-0248.2006.00919.x.

38. Michał Filipiak; Nutrient Dynamics in Decomposing Dead Wood in the Context of Wood Eater Requirements: The Ecological Stoichiometry of Saproxylophagous Insects. Ulyshen $M$, editor. Saproxylic Insects Diversity, Ecology and Conservation 2018, 1, 429-469, 10.1007/978-3-319-75937-1_13.

39. Michał Filipiak; Pollen Stoichiometry May Influence Detrital Terrestrial and Aquatic Food Webs. Frontiers in Ecology and Evolution 2016, 4, na, 10.3389/fevo.2016.00138.

40. Łukasz Sobczyk; Michał Filipiak; Marcin Czarnoleski; Sexual Dimorphism in the Multielemental Stoichiometric Phenotypes and Stoichiometric Niches of Spiders. Insects 2020, 11, 484, 10.3390/insects11080484.

41. Michał Filipiak; Karolina Kuszewska; Michel Asselman; Bożena Denisow; Ernest Stawiarz; Michał Woyciechowski; January Weiner; Ecological stoichiometry of the honeybee: Pollen diversity and adequate species composition are needed to mitigate limitations imposed on the growth and development of bees by pollen quality. PLOS ONE 2017, 12, e0183236, 10.1371/journal.pone.0183236.

42. Michał Filipiak; Key pollen host plants provide balanced diets for wild bee larvae: A lesson for planting flower strips and hedgerows. Journal of Applied Ecology 2019, 56, 1410-1418, 10.1111/1365-2664.13383.

43. Michał Filipiak; A Better Understanding of Bee Nutritional Ecology Is Needed to Optimize Conservation Strategies for Wild Bees-The Application of Ecological Stoichiometry. Insects 2018, 9, 85, 10.3390/insects9030085.

\section{Keywords}

ecological stoichiometry;ecology;ecosystem ecology;nutrient cycling;food web;food chain;nutritional ecology 